The Hard of Hearing Child. Clinical and Educational Management. By FrEDERICK S. BERG and SAMuel G. Fletcher. (Pp. ix $+363 ; 19$ figures + 38 tables. \$12.75). London and New York: Grune and Stratton. 1970.

The purpose of the editors has been to make available for those concerned with the management of the hearingimpaired child information from a wide variety of disciplines. They perform a valuable service by including chapters on subjects of fundamental importance to the acquisition of spoken language. The advances in acoustic phonetics, and the nature of language and its development in the child, have yet to be incorporated into the teacher's approach to the child, and educational management will continue to suffer until they are. But why a discussion on operant behaviour in the laboratory animal ? Despite its possible application in certain forms of language disorder, the Skinnerian approach appears to have little to offer the hearing-impaired child. The second half of the book is concerned with the practical management of the child and the ground is covered by chapters on case history taking, psychological examination, the planning of educational programmes, and the use of the various teaching media, concluding with a well-argued plea for a better understanding on the part reading has to play in the child's learning and development.

In a book presenting a comprehensive survey of the hearing impaired child, it is disappointing that medical aspects receive no attention. Despite the subheading 'Clinical and Educational Management' there is no discussion on the middle ear except in a chapter on anatomy and physiology-which could well have been omitted since lesions of the different parts of the auditory system are not considered. Common causes of damage to hearing and their implication for differential diagnosis and teaching, and the complex interaction of multiple handicaps which may arise from, say, rubella or kernicterus, are not mentioned. This limits the interest and value of the book for medical readers. On the educational side one would have liked to see more emphasis on the problems and the details of management of the pre-school child, the most important and neglected aspect of hearing-impaired children. The time is long past when the benefit of auditory training can be described in terms of a single case report, particularly if it happens to be a contributor's child. There are remarkable success stories concerning individual children with severe hearing losses but we need to be educated on the causes of failure in the numerous children with less severe degrees of impairment.

Parents and teachers will continue to blame each other for poor results until all responsible are fully conversant with the wide variety of factors, auditory, cognitive, psychosocial, linguistic, and even perhaps neuromotor, which impair acquisition of spoken language. We are only now beginning to understand the significance of such factors in the 'normal', uncomplicated hearing-impaired child. This book makes a valiant attempt to point up some of these problems.

\section{A Practical Guide on Hearing Impaired Children.}

By Alfred L. Miller and Roger H. Lehman. (Pp. viii +69 ; 6 figures. \$5.50.) Springfield, Illinois: Charles C. Thomas. 1970.

This short book covers in three chapters, medical aspects of deafness, hearing testing, and hearing aids.

After a review of the anatomy and physiology of hearing, the causes of deafness are discussed, though one or two such as presbyacusis must be uncommon in children. Hearing testing is virtually confined to pure tone audiometry, and there is little indication of the procedures appropriate to different ages of children, particularly in the under $5 \mathrm{~s}$. From 5 years and up the problems are essentially similar to those encountered in adults.

The final chapter on hearing aids gives an illuminating series of questions commonly asked by parents, which are well answered by the writer. It would have been helpful for numerous overoptimistic parents to point out that wearing a hearing aid is but a part of the whole process of rehabilitating the child with a hearing loss. The descriptions of different types of aid and their management is simple and clear.

With the exception of the section on hearing testing, this would be a useful book for intelligent par nts to read, though its rather high price for 65 pages might have a limiting effect.

The Coeliac Handbook. Edited by B. Nilson. (Pp. 88; illustrated. 80p.) London: The Coeliac Society. 1970.

The Coeliac Society was founded only in June 1968 and is to be commended for already putting out this practical handbook for the benefit of 'coeliacs', both children and adults. A short history of the disease leads on to a well-illustrated account of what is known about its cause, and the rationale of treatment. The main part of the book is made up of a large number of cooking recipes, which seem to cover adequately all the items, from Christmas pudding to ice cream, that might ordinarily have wheat flour as an ingredient. There is also a list of manufacturers (and their addresses) who make special gluten-free products, and an up-to-date (1970) list in a separate pull-out supplement of manufactured foods which are known to be gluten-free. The one criticism is that for a cookery book its paperback format may prove insufficiently robust. This invaluable publication gives us an additional reason for remembering to bring to the notice of our coeliac patients the existence of the Coeliac Society (116 Loudoun Road, London N.W.8). 